\title{
Civic Engagement Scholarship: What We Can Learn from the Research
}

\author{
David Hurley \\ Master of Public Affairs Student \\ Indiana University South Bend \\ hurleyda@iu.edu \\ Kayla Isenbletter \\ Master of Public Affairs Student \\ Indiana University South Bend \\ kisenble@iu.edu \\ Elizabeth A. Bennion \\ Professor of Political Science \\ Indiana University South Bend \\ ebennion@iu.edu
}

\begin{abstract}
$\underline{\text { Abstract }}$
PS: Political Science and Politics is focused on critical analysis of teaching methods, research, and professional development in the field of political science. It is a vital resource for educators and researchers to investigate trending topics and methods for teaching civic engagement. This literature review highlights articles about teaching civic engagement published in PS: Political Science and Politics over the past decade. The authors summarize the articles to provide a quick overview and useful reference for those who teach civic engagement in the political science classroom; they also explore the core themes of the 2021 Annual Meeting of the American Political Science Association, including the overall theme of promoting pluralism. Highlighted articles focus on global and pluralistic approaches to civic engagement, including crossdiscipline collaboration and experiential learning practices that provide actionable, practical, and broadly relevant models of civic engagement pedagogy.
\end{abstract}

Prepared for the Annual Meeting of the American Political Science Association, Seattle, Washington, September 30 - October 3, 2021

\section{Introduction}


Record setting turnout in the 2020 presidential election belies the fact that the state of civic discourse in the United States has reached a historic low. While record numbers may be engaged through the ballot box, political divisions and the vitriol characterizing political debate only seem to grow. A lack of consensus around basic facts and the lack of rudimentary knowledge of our civic institutions have been among the core factors contributing to this discord. John Dewey famously said, "Democracy has to be born anew each generation, and education is its midwife." Students must learn the skills required for democratic citizenship. Civic skills include the ability to communicate with elected officials, organize to influence policy, understand and participate in one's polity, and think critically about civic and political life, as well as the ability, and desire, to deliberate with others about the public good. In the wake of a disputed presidential election, an attack on the capital, and the politicization of a global pandemic resulting in large numbers of preventable deaths, the need to promote civic knowledge, skills, and dispositions is clear. The rise of populist authoritarianism and nationalism worldwide, combined with growing distrust of institutions and democracy itself, highlight the gravity of the situation (Kwak et al. 2020). In this moment, it behooves educators to turbo-charge civic engagement in order to cultivate constructive citizenship among students from secondary school to graduate programs.

Fortunately, scholars have been advancing our knowledge of civic engagement pedagogy over the last decade. Dozens of articles in leading political science journals like PS: Political Science \& Politics and the Journal of Political Science Education have shared research and insights into this burgeoning field. Several years ago, a literature review article, "Best Practices in Civic Education: Lessons from the Journal of Political Science Education" (Bennion \& Laughlin 2018), distilled some of these insights to provide a resource to scholars in civic education by summarizing what others have done, highlighting lessons learned, and making suggestions for future research.

The time is ripe for an expanded literature review to discover civic engagement pedagogies crucial to helping us to address the critical issues facing our country, and world, today. We find ourselves at a critical juncture in our civic environment. A substantial number of citizens do not presently recognize the legitimacy of our government, and thousands were mobilized to overturn the democratic processes we once held sacred. We are in the uncertain midst of reckoning with this phenomenon, and the outcomes are pending. We are acutely aware of the urgency of the situation, and this literature review, which summarizes research and practice in civic engagement from one publication over the last decade, is our response to the moment.

\section{Methods and Limitation of Review}

PS: Political Science \& Politics is a quarterly peer-reviewed academic journal covering all aspects of contemporary political phenomena and political science, published by Cambridge University Press on behalf of the American Political Science Association. The journal was established in 1968 as PS, obtaining its current title in 1988. The Teacher section is intended as a practical resource for those directly involved with instruction and curricula development and as such has more relaxed research criteria, and a greater focus on pragmatic and easily adaptable models, than many top-tier academic research journals. We have selected articles to review from PS: Political Science \& Politics that in some way inform civic education designed to promote civic knowledge, skills, and engagement. Our analysis provides a basic overview of these articles so that practitioners and scholars can quickly and easily reference the research and practices 
reflected in these articles and use these when designing their own course curriculum and assignments. A good many of these papers provide best practices or detailed descriptions of initiatives for easy replicability. This literature review has the modest intent to survey the works described herein in order to identify useful, actionable and broadly relevant research and practices that can easily be deployed to address the crises we currently face.

The urgency of advancing the pedagogy of civic engagement motivated us to include articles that focused more on practical application than rigorous research methodologies. However, the importance of the subject demands we be vigilant in understanding what works well. Therefore, attention to assessment methods and tools must remain a priority. The most utilized method of assessment in the articles examined was surveys. Twelve instructors employed pre-and postcourse surveys to determine how their teaching method impacted student learning outcomes. The type of survey varied, with some instructors preferring formal written surveys, and others resorting to informal discussion-based surveys within the classroom. Writing assignments and course reflections were also a popular assessment tool, with eleven instructors opting for written testimony and research from their students to determine the efficacy of their instruction model. The tools used to gather these reflections varied from requiring students to write diary entries to the assembly of blogs where students post their thoughts on the material and respond to posts from their classmates. Other assessment methods include student interviews, pretest/posttest exams to gauge knowledge of the course topic before and after a specific pedagogical intervention, course evaluations, supervisor/educator evaluation of course goal progress and onsite work performance, randomized experiments, direct measures of behavioral change (e.g. official voter files measuring changes in turnout), and content analysis of class discussions.

This review focuses almost exclusively on "The Teacher" section of PS: Political Science and Politics from January 2010 to October 2020 and thereby is heavily weighted towards articles intended to serve as resources for instructors and those involved with developing curricula. There are a good number that share a model for a specific course or program that can be replicated by others. As such, many articles had limited assessment tools - often relying on content analysis of student reflections or very small sample size to evaluate findings. While it is important to encourage more rigor in assessment methods, we share these models in hopes that others may utilize these works to build upon existing knowledge and expand the learnings that can be derived from replication. We also highlight those endeavors that apply more rigorous evaluation methods, such as pre-post survey comparisons and longitudinal metrics that provide quantitative and/or qualitative evidence of the efficacy of various interventions.

This literature review highlights $P S$ essays that specifically focus on effective ways to promote civic knowledge, dispositions, and engagement. In order to identify relevant articles for this project, we accessed the online version of PS: Political Science \& Politics and used the search box to identify articles related to this theme. Key search terms included: civic engagement, experiential learning, service learning, community engagement, and civic education. After an article was identified as fitting the search parameters, the authors carefully reviewed the article to determine whether the focus on civic engagement was primary and intentional, or merely incidental or secondary to the primary purpose of the article. This winnowing process is necessary to avoid the assumption that all political science education is civic education, or training for engagement. 
Using this approach, a total of 24 articles were selected after reviewing 10 volumes, and 40 issues of PS (from 2010 to 2020). All but one of the articles were published in "The Teacher" section of the journal, the exception coming from "The Profession" section which provided useful information on conducting research in high schools. This includes the work of 82 teacherscholars from 50 different institutions including community colleges, liberal arts colleges, regional universities, and research-intensive universities in multiple U.S. states and overseas. The articles included were topically and methodologically diverse, ranging from single class case studies to multi-campus field experiments.

\section{APSA Conference Themes}

Like the civic engagement work of our students, the writing of this paper takes place in a specific context. The framework of this paper reflects this context, as analysis is structured, in part, to highlight the themes of the 2021 APSA Annual Meeting.

In the recent past, the problem of diminishing participation in political processes has driven imperatives around civic engagement. But our situation seems to have shifted such that we find ourselves at a point where group identities, a kind of neo-tribalism, seem to override the kind of deliberative process we assume characterizes civic engagement and democratic deliberation in a pluralistic society. APSA's 2021 annual conference theme of "promoting pluralism" acknowledges the need to concentrate on breaking down the silos that separate us. In explaining the 2021 APSA conference theme of "Promoting Pluralism," APSA President Janet BoxSteffensmeier asserted that "the most well-recognized dimension of political science's pluralism is methodological." Accordingly, she invited the "messy, the inconclusive, and the hard to interpret, right along with the precise, the clear, and the parsimonious."

Perhaps one of the most important ways to promote pluralism is to facilitate civil discourse by teaching empathetic and reasoned debate. The decline of constructive political dialogue may be the single most prominent symptom of the political crisis we currently face. Therefore, we highlight examples that attempt to cultivate the skills and values that underlie political and civic civility among citizens. Debate and conflict can be healthy if combined with conflict resolution and honest deliberation that values all voices and centers equity, inclusion, reparation of harm, and the common good.

We also explore models that encourage cross-disciplinary collaboration. By definition, "engagement" implies interaction in the world beyond the academy which necessitates intellectual engagement with fields and disciplines outside the traditional boundaries of political science education (Matto, et.al. 2017). Tackling "wicked problems" - which include big challenges like climate change, global conflict, an aging population, and immigration - requires an interdisciplinary framework that includes, but is not limited to, insights about government and politics (Rittel and Webber 1973; Theis 2016; Simeone, Sikora, and Halperin 2017). Civic learning can occur through service-learning, and other forms of community-based learning, in disciplines across the spectrum of the liberal arts as well as sciences, engineering, etc. This review of the articles published in $P S$ over the past decade will seek out and highlight examples of educators and political scientists attempting to implement strategies for civic learning and democratic engagement across a variety of methods and disciplines that include simulations and other active learning strategies. 
Increasingly, research in civic engagement is happening globally or addressing issues like climate change that straddle local and global contexts. Examining civic engagement from a global perspective offers opportunities to learn from diverse cultural contexts with civic traditions different from our own. As the APSA's newly released book Teaching Civic Engagement Globally demonstrates, the way that civic engagement is pursued in authoritarian contexts, and other illiberal or less liberal contexts, may be revelatory in our rapidly changing global community (Matto, et al. 2021).

Moreover, the tectonic shift in the information ecosystem demands that we proactively address this sphere. Until recently, regular attention to established news sources was critical in establishing the civic knowledge needed for meaningful political and civic participation. But now, with the prevalence of social media, and the toxicity of that information stream, our information channels sometimes do more to undermine pluralism and constructive forms of civic engagement. Social and digital media is rapidly evolving and increasingly affecting our civic discourse. Misinformation and disinformation is widespread in the U.S. and worldwide. Even UNESCO created a handbook for journalism education and training entitled: "Journalism, 'Fake News' and Disinformation" (available at en.unesco.org/fightfakenews).

Based on this reality, civic educators are seeking ways to use digital technology productively to encourage civic learning and democratic engagement in both online and offline arenas (see, for example, Mike Caulfield's Web Literacy for Student Fact Checkers and free online digital literacy course at hapgood.us). Scholars have increasingly sought ways to transform online platforms to reduce social divisions, build social capital, and defeat political tribalism (see, for example Duke's Political Polarization Lab and Chris Bail's 2021 book Breaking the Social Media Prism: How to Make Our Platforms Less Polarizing). In the meantime, reviewing this emerging literature may provide useful insights for working within the current social media landscape, as well as new approaches to teaching, research, and social media consumption going forward.

\section{Findings}

\section{Cross Disciplinary Collaboration}

In the field of civic engagement pedagogy, there is a growing recognition that methods and knowledge within the field of political science must not be confined to a single discipline and that all academic areas stand to benefit from and contribute to civic knowledge. A strong sense of collaboration across disciplines should become the norm. Several articles in PS: Political Science \& Politics place special emphasis on this cooperative goal. Civic education has been integrated into subjects such as economics, literature, and media studies. In the following section, the benefits and challenges of cross-disciplinary efforts are examined to provide a framework for educators seeking to improve and expand their pedagogical reach.

Collaboration across disciplines to teach the values of civic engagement is exemplified in Craig Borowiak, Vicky Funari, Jesikah Maria Ross, and Helen K. White's article, "Troubled Waters: Tracing Globalization and Waste in the Delaware River" (Borowiak et al. 2017). This study was conducted at Haverford College and included students from introductory political science, chemistry, and documentary film courses, as well as community media artists and other 
community partners. The goal of the project was to study the number of pollutants in the Delaware River, where those chemicals came from, and how to present the findings in a compelling way on screen. The project also sought to engage the students with the community and local civic processes. By studying pollutants present in the river, students tracked the chemical sources to various corporations in the surrounding area. This prompted them to research the policies that allowed corporations to dump waste into the river, how those policies might be changed, and how this waste impacts the communities that rely on the river's water. In course evaluations, participating students reported learning more about the consequences and causes of pollution through collaborative efforts than they would have solely within their discipline. For example, the film and chemistry students explained that they benefitted from the fact that this course required them to learn how to communicate about their field to those that are less knowledgeable on the subject. It also encouraged them to interact with the community outside of campus and to delve into topics that they were unfamiliar with and develop skills and experiences useful in navigating civic life outside of the classroom. The authors highlight key supports that would be necessary for others attempting to replicate the project. First, the project appointed Jesikah Ross, a media artist, as the point person for communication between the educators and participants across participating classes as well as community partners like Delaware Riverkeeper. Ross also facilitated meetings with research librarians and field trips for each class. A large and collaborative project such as this requires a great deal of communication and coordination between groups, and a designated individual to oversee this was helpful. Additionally, campus librarians provided custom research and resource guides for the participants and made themselves available throughout the semester for research assistance and technical support, which was vital for sharing the project online. Finally, the cross-class collaboration element of the project was prioritized through regular meetings of all involved courses. Without this, students would not have had the ability to share and workshop their findings, which were presented to the campus community and general public during a four-hour interactive event.

This project required intensive involvement and thus the authors concluded that the student commitment to service learning was crucial. Service-learning outcomes from reluctant students is an important element to explore in experiential pedagogies as well. Thomas Knecht and Lisa Martinez in "Engaging the Reluctant? Service Learning, Interpersonal Contact, and Attitudes toward Homeless Individuals, (discussed more below) looked closely at differences in outcomes between students required to engage in a service-learning activity and those who voluntarily chose to participate (Knecht and Martinez 2012). Though data was limited, comparisons from pre- and post-test surveys of students involved in a service-learning project focused on homelessness indicated a higher impact on attitudinal change among students who were required to participate in the activity. Depending on the nature of the course and the service activity-- there are instances in which there may be advantages to requiring service-learning among students who might otherwise be resistant. Also, some of those "reluctant" students came from disciplines outside of political science, for which involvement in a community service project was outside the norm of their disciplines. Nonetheless, the Troubled Waters article describes a particularly complex project demanding a level of collaboration that is time consuming, and educators should be aware of the time each stage of the project requires to ensure that there is not a significant time lag between each discipline's responsibilities. Finally, collaboration across courses, rather than co-teaching, allowed each educator to accomplish their pedagogical goals, and receive full (FTE) credit, while maintaining cooperation. 
Engaging reluctant students often requires that educators build student confidence in engaging in the political process. Methods for achieving this are detailed in "Blending Elements of Economics and Political Science: Intergenerational Dialogue, Civic Engagement, and Related Student Scholarly Activity" by Rob Catlett at Emporia State University. Here, the America's Future Initiative was introduced to participants in a comprehensive beginning economics class and intermediate micro- and macro-economics courses. These students were provided with a pre-survey to gauge their knowledge and perceptions of economic issues in politics, such as deficits and debt. Students were then tasked with creating a survey to facilitate intergenerational dialogue between themselves and older family members on these topics. Inclass efforts were complemented by community civic engagement projects, including a partnership with KansasWorks to formulate a plan to allocate federal stimulus funds to a summer youth employment program. These efforts culminated in a national competition where students featured their work from the initiative. Many students in the pre-survey expressed concerns with not being good or competent enough to participate and compete at this level. However, through these projects, students reported less discomfort and feelings of not being good enough throughout the semester. Several students also won awards for their work in the program, including twelve students who won awards nationally, and came from a variety of cohorts and majors. Although quantitative data is not provided, researchers also found that student performance in the course improved with each project, and student and educator surveys found that student attitudes towards the elderly and providing social welfare for them improved through intergenerational dialogue (Catlett, 2010).

While students and educators can collaborate using their individual knowledge to engage civically, they can also use their knowledge of civic engagement and politics to improve their disciplines. This can be seen in Michael Smith and Bob Graham's article, "Teaching Active Citizenship: A Companion to the Traditional Political Science Curriculum" which distinguishes between teaching citizenship and teaching civics (Smith and Graham 2014). They argue citizenship is taught most effectively by engagement in real world issues and in changing policy that has direct relevance to student's daily experience, promoting a bottom-up approach to civic education based on issues of immediate relevancy to students. Students may be more interested in traffic at an intersection near their school than in more high-profile issues - whether local or national - that may be "in the news." The article presents a lesson outline premised on the idea that the most powerful lessons will be derived from experiences that closely parallel students' own life experiences and that encourage students to engage in "hands on activity to change the status quo." Such an approach has potential to cross disciplines because the specific issues may have little to do with politics per se, but addressing them requires students to engage with the government and cultivate civic knowledge in the process.

\section{Experiential Learning}

Political science instructors engage students in a wide range of experiential learning activities. For an overview of the range of approaches in the field see Elizabeth Bennion's chapter on experiential education in The Handbook of Teaching and Learning in Political Science and International Relations (Ishiyama et al. 2015). Experiential learning encompasses a wide array of activities from community-based service learning to more controlled simulations. Articles reviewed here encompass a variety of experiential learning examples: volunteering at organizations that serve underrepresented populations, hands-on political learning through the 
development of legislation and exit polls, and other activities that expose students to their communities and local political realities.

Often, the goal of experiential learning is to encourage students to apply what they have learned about politics and civic engagement in theory and practice in a way that benefits their communities and gives them a real-world perspective. "Student-Run Exit Polls 101" by Croco et. al. accomplishes this objective by engaging students in the development of an exit poll that was administered to 2,300 individuals (Croco et al 2019). This not only exposed students to the polling process and the opinions of their fellow citizens, but also taught them about the ethics and mechanics of developing a survey and how to analyze the data they gathered. A similar design was employed by the authors of "Pedagogical Value of Polling-Place Observation by Students," where the participants were tasked with observing polling places as a type of field research (Mann et al. 2018). Students were encouraged to apply the lessons that they learned in the classroom about voting and civic participation and document those principles occurring in practice. In "An Entrance to Exit Polling: Strategies Using Exits Polls as Experiential Learning Projects," Michael Berry \& Tony Robinson make the case that exit polling exercises not only provide experiential learning opportunities but can help overcome students' aversion to instruction in social science research methods. As such, they are also uniquely positioned to teach principles of research design in a way that is broadly accessible to students from diverse disciplines (Berry and Robinson 2012). The article describes an election polling process for the 2008 and 2010 elections in Denver that entailed designing, analyzing and administering exit poll results. Such projects, however, can be challenging to engage in due to their complexity and the intensity of the work required of both instructors and students. Thus, the authors provide this article to serve as a primer of sorts in order to facilitate the process for others.

This type of experiential learning can also be augmented by simulations, as they are in "Service Learning and Simulations" by Shannon Jenkins (Jenkins 2010). Jenkins found that service-learning experiences were useful in exposing students to the issues in their community, and that simulation that followed these community-based learning experiences provided students with the political context they needed to understand why ongoing social problems exist and how to enact positive change through the legislative process. Without both aspects of the project students would have an incomplete theoretical and practical understanding of the challenges that exist in their communities. The combination of the methods made students more aware of key issues in their community and more knowledgeable about civic processes and political procedures. An analysis of affective outcomes in both the departmental course evaluations and pre- and post-test surveys conducted supports the conclusion that combining service-learning with simulations have a meaningful impact on students' civic knowledge.

Sara Rinfret describes another use of simulations in the context of local government in “Simulating City Councils: Increasing Student Awareness and Involvement" (Rinfret 2012). While national political dynamics can be dominant in thinking around political science, local politics often have greater immediacy in individuals' day-to-day experiences. Political science students get thorough exposure to federal institutions, but how well do they engender civic knowledge and encourage participation in municipal issues? Rinfret details a simulation of local, city council meetings to help students become better informed on local policy making issues. Citing data on low levels of participation in local government elections, Rinfret questions how well civic knowledge and participation are cultivated among students at the university level. 
She details a simulation exercise she's developed to address this need, allowing for easy replication. Insights on how students will be evaluated and graded are useful for instructors who would like to implement such a simulation. Having refined this exercise over five terms, Rinfret's observations and suggestions are highly useful in making this exercise readily applicable. Evaluating the impact of the simulations relies on students' anecdotal feedback, but one insight that is valuable is that this exercise may have broad applicability across disciplines, because the specific issues addressed can relate to multiple academic disciplines. Because local policy matters are often broadly relevant complex issues, an interdisciplinary approach is useful and past student participants have suggested that the simulation would be useful to include in a general education course so that all students would benefit.

The potent impact of simulations is convincingly demonstrated by a study that backed its conclusions by providing longitudinal data regarding student learning outcomes and interest in civic engagement. Few authors included longitudinal data, despite the fact that it is essential to assessing success in achieving the ultimate goal of civic education: a lifelong attitudinal and behavioral change. Longitudinal data can provide valuable information about the long-term impact of specific interventions on future attitudes and behaviors. For example, in "Simulating 2008: A Mock Presidential Elections (MPE) Impact on Civic Engagement," Jenna Deitz and Keith Boeckelman demonstrate the value of experiential learning experiences using assessment tools including follow-up surveys -- one immediately following the simulation and another one year later. (Deitz and Boeckelman 2012). By conducting a survey assessing civic knowledge and interest to a broad control population and simulation participants a full year after, the authors bolstered their findings showing the efficacy of the mock election event on civic knowledge and engagement. This one-year follow-up compared measures of political knowledge, interest and engagement among participants in the MPE and others on campus who did not participate. By showing statistically significant (non pre-existing) differences in the different populations' interest in politics and public affairs, the survey results robustly demonstrate the efficacy of the simulation.

In addition to educating students on civic principles and practices in the field and teaching them useful skills, simulations, service learning and other forms of experiential learning have been utilized to encourage students to address community issues and become "change agents." The intersection of these goals is addressed in Gerlach and Reinagel's "Experiential Learning in MPA Programs: A Case for Complementarity between Internship and Service-Learning Requirements," where the authors confirm the success of internships that value profitable and practical skills and service learning that develops a passion for advocacy while encouraging educators to engage their students in both (Gerlach and Reinagel 2016). The authors articulate the value of experiential elements in Public Administration Master's curricula, but the most efficacious ways to accomplish these aims remain an open question. The accrediting body for MPA programs - the Network of Schools of Public Policy, Affairs and Administration (NASPAA) - has tracked internships more than service-learning, so this article brings value in addressing how service-learning pedagogies can be a part of MPA programs and draws attention to the need for NASPAA to provide guidance on service-learning elements for MPA programs. After elaborating on the various applications of each approach to experiential learning, the authors argue that the two approaches are ideally complementary. They ultimately encourage administrators and educators in MPA programs to use both approaches to strengthen MPA 
pedagogies and, importantly, to be cognizant of the meaningful benefits such methods of experiential learning might bring to local communities.

Similar to Gerlach and Reinagel's research, "Problem-Based Learning and Civic Engagement - Shifting the Focus of Learning in Public Policy Education" by Chris McInerny and Maura Adshead examines the benefits of problem-based and experiential learning in civic engagement pedagogy. The goal of this project was to allow students to examine a policy "problem" -- the local implementation of the National Spatial Strategy in Ireland -- and formulate solutions as a group with the surrounding community. The National Spatial Strategy is a 20-year strategic planning framework for Ireland that seeks to improve social, physical, and economic development across the country, and the local development of this national policy served as the problem or task for students and community members to solve. Students were required to engage in three types of interactions: public space interactions with community members that may not regularly attend community events, targeted interactions with policy stakeholders, and structured invited interactions with community members in a town hall. Through these interactions and simulated community interactions in the classroom, students developed an understanding of the problem and potential collaborative solutions. Assessment was conducted through student reflection, in which students reported positive learning outcomes in the areas of political communication and listening, participation and deliberation in the political world, knowledge of public and private interests in their communities, and developing an interest in politics.

Unfortunately, not all communities offer the same opportunities for engagement. The context and community in which a campus is located may prove to be a significant challenge to instructors seeking diverse, high impact, community-based civic learning opportunities. This is addressed in Brian Anderson's "High-Impact Political Science Internships in a 'Low-Density Opportunity' Environment" (Anderson 2014). A "low density opportunity environment" is defined by the authors as a university that is situated in an area that is far from a capital city or metropolitan area, which requires them to place students in internships with small-city administrations, nonprofits, and local offices of state or federal agencies. While internships, service, and experiential learning in "low-density opportunity" areas may struggle to provide participants with the chance to engage with various groups of people and the issues they may face, Anderson finds that educators can frame students' learning environment as opportunities by stressing the increased transparency, easier access to decision-makers, and reduced hierarchy that smaller communities provide. By placing students in small governmental or community organizations, students are more likely to be exposed to the inner workings of the group and become a more integral part of the legislative process or advocacy effort to which they have been assigned. This ensures that they are gaining the professional skills, civic knowledge, and passion necessary to become effective, engaged citizens (regardless of their legal citizenship status).

While a tendency to engage students in a one-time experiential learning event still exists, educators are seeing the benefits associated with long-term community engagement and experiential learning endeavors. This can be seen in "Think Globally, Act Locally: Community-Engaged Comparative Politics," by Amy Risley (Risley 2019). In this study, students were placed with community organizations that addressed homelessness, refugees, and Latinx communities with the intent of exposing them to community-based activism that is informed by global conditions. This can be contrasted with the "Engaging the Reluctant? Service Learning, Interpersonal Contact, and Attitudes toward Homeless Individuals" 
article mentioned previously (Knecht and Martinez 2012). The students in this study were required to take part in an activity that lasted a single day, where they were tasked with escorting homeless individuals to various booths providing services they may need. Knecht and Martinez did find that attitudes about homeless people changed and became more positive in their posttest assessments, and those students who were required to take the course experienced more substantial attitudinal changes than those that elected to participate, pointing to the self-selection problem that affects many studies of civic learning. Those who might be most strongly affected by civic learning experiences are the least likely to engage in such experiences. Meanwhile, those who already have a strong sense of political efficacy and a strong interest in community engagement seek out opportunities to fulfill these needs. Even when participation is required or participants are randomly selected, it can be difficult to determine the long-term effects of such experiences or the effects of repeated engagement over time. Risely, Croco, et al. and many others acknowledge this limitation in their studies, which supports a need for longitudinal studies and replication. Another challenge is linking attitudinal change about communities, populations, and social problems to attitudes toward public policies designed to help such communities and mitigate against specific problems. A comparison of the pre-post- test surveys completed by Kneckt and Martinez's students, for example, indicated no change in their attitudes around public policies dealing with the issues of homelessness.

Experiential learning and community-engaged projects offer a wealth of benefits for students and the organizations they partner with; however, it is vital that educators and their students proceed with caution and awareness of the community and their role in it. Risely, for example, dedicates a section of the course in the very beginning to ensure that students are not participating with the intent to "fix things," or to be a "savior" for the underrepresented groups they are serving. Instead, they should seek to develop working relationships that are mutually beneficial to the participant and the communities being served. This concept is also addressed in "Ethnic Studies as a Site for Political Education: Critical Service Learning and the California Domestic Worker Bill of Rights" by Tania Mitchell and Kathleen Coll (Mitchell and Coll 2017) which posits that a critical service learning (CSL) approach - which approaches service learning with an explicit social justice aim - offers a departure from "traditional service learning" which risks a de-politicized exercise in which students engage in charitable endeavors which focus on the symptoms of systemic disparities rather than understanding the deeper dynamics at play. The CSL approach makes a commitment to a just and equitable society explicit in order to help students experience the transformative potential of active political engagement.

In this study, students were tasked with participating in a grassroots movement with California Domestic Workers Coalition and the National Domestic Workers Alliance to pass the California Domestic Workers Bill of Rights. Active work with community activists lobbying for the rights of domestic workers provided opportunities for students to learn from a wide range of actors, while classroom readings and writing reflections helped students to recognize their family histories relevant to domestic worker rights.

By working on an existing campaign being directed by community advocates, students were being "instructed" by those whom they might otherwise consider to be "recipients" of their "services." Students derive similar lessons in a project conducted by Charles Turner in "Civic Engagement in the Capstone: The 'State of the Community' Event," where students were required to present a SWOT analysis and a State of the Community presentation to municipal 
agencies and community members. Acting as consultants, they first had to learn from public administrators and community members to better understand the strengths, weaknesses, opportunities, and threats that already existed in the community (Turner 2014).

Students participating in a similar study may be tempted to be the "savior" or "hero" of the movement, without recognizing the work that existing advocates and leaders have done to ensure the success of the project. This would also undermine the needs and demands of the people that stand to benefit from the project while prioritizing what the participants think is wanted or needed for the community to succeed. Mitchell and Coll also recognize and emphasize the importance of educating students on this as well as their privileges within their local and global community. This step, part of the increasingly popular critical service-learning perspective, is vital to ensuring that students become partners in their communities rather than uninformed or overbearing allies.

\section{Globalism}

With the launch of a new book on Teaching Civic Engagement Globally (Matto et al. 2021), the American Political Science Association joins professional associations worldwide in recognizing that civic learning and democratic engagement are topics that must be taught across the curriculum and throughout the world. There is a wide variety of approaches to global civic engagement. Within a domestic university setting, global civic engagement can be difficult to accomplish. In "Civic Engagement with an International Focus: The Western Carolina Microfinance Project," Michael McDonald enumerates different possible approaches to the problem by outlining three models: Place-bound interactions, transborder service learning, and international service-learning (McDonald 2013). Place-bound service learning, as articulated by Luis Cabrera and Jeffrey Anstasi (Cabrera and Anatasi 2008) is a form of engagement in which students participate in service-learning opportunities in their local communities that link them to the global community, such as working with immigrant or refugee communities. Transborder service learning entails working with populations or issues across international boundaries, but do not necessarily require international travel. The "Troubled Waters: Delaware River Project (Borowiak, et al. 2017) discussed earlier is an example of place-bound service learning. International service-learning entails traveling across international boundaries to conduct service in a non-native country (McDonald 2013). The Western Carolina Microfinance project provides an actionable way to implement the transborder model without actually traveling internationally. This is a particularly feasible method to expose students to a global service-learning experiences without the burden of time and resources needed for travel. Like many emerging pedagogies, this model demonstrates the creative use of a digital media platform to facilitate student interaction across national boundaries.

McDonald designed an international civic engagement course without leaving campus by using the digital platform KIVA which facilitates micro-finance arrangements by directly linking micro-enterprises to prospective lenders. By using the platform, students were able to identify entrepreneurs in developing countries for whom a micro-loan would have a significant impact on their enterprise. The course also provides academic components through regular readings, discussion and reaction papers.

In “Thinking Globally, Acting Locally: Community Engaged Comparative Politics," Amy Risley builds upon the strong community engagement orientation of Rhodes College to link 
student community service as part of a course entitled "The Politics of Social Movements and Grassroots Organizing" that exemplifies the place-bound model of civic engagement on global issues (Risley 2018). The course focuses on urban movements involving marginalized communities and builds upon Rhodes College's community service requirements by coupling student service with refugee and immigrant communities to course materials that help promote intercultural awareness and provide a global context to what students encounter in their local service placements. Risley shares a framework borrowed from Westheimer \& Kahne (2004) to evaluate different kinds of citizenry: personally responsible citizens, participatory citizens and justice-oriented citizens and uses this framework throughout the course to evaluate servicelearning experiences. Early stages of the course require the instructor to be intentional about laying a groundwork in social movement theory for students to gain the most from their experiences. The importance of linking class instruction with experiential learning is emphasized, while the challenges of incorporating both elements in a course are acknowledged. Consistent with previous research, specific challenges identified include the problem of limiting service engagement within the constraints of the academic calendar. Such limits on the timeframe can lead to frustration for both students and community-based organizations with the inability to follow through on engagement experiences. Moreover, placement with community organizations requires additional resources and efforts that may be onerous on instructors if an institution lacks an established community engagement capacity such as an existing service center on campus. Such obstacles place greater demands on instructors who may otherwise seek to implement such a course. Risley's previous research on civil society and social movements as well as Rhodes College's institutional commitment to service-learning, not to mention their location in a large metropolitan center, helped mitigate some of these challenges.

\section{Social and Digital Media}

Social and digital media is increasingly being used as a tool to improve students' political awareness and civic engagement. With an ever-widening selection of platforms for educators to utilize, there are endless possibilities for lesson planning relating to public policy, political discourse, research, and political empathy. Nearly all information that one might need on a political topic can be found online, and this is incredibly useful for those trying to become more knowledgeable about civic processes. Digital media platforms can also be creatively used to bring global issues into the classroom, as McDonald showed in the Western Carolina Microfinance Project discussed above, which allowed students to use the platform Kiva to directly participate in an international community by working directly with unbanked entrepreneurs across the globe (McDonald 2013). However, beyond merely learning about politics and civic life, digital and social media allows the user to act through persuasive writing, discourse, and organizing for a political cause. As media usage becomes increasingly ubiquitous, it is vital that educators find ways to incorporate social media into their discussions and lessons about civic engagement to give students the confidence and passion to have difficult conversations with their peers and the competency to take what they learn online into their realworld engagement experiences.

Engagement in discourse relating to politics and civic life can occur on various platforms. Jennie Sweet-Cushman opted to study how Twitter can be a vehicle for these conversations in her article, "Social Media Learning as a Pedagogical Tool: Twitter and Engagement in Civic Dialogue and Public Policy" (Sweet-Cushman 2019). This was accomplished by developing a 
framework known as Class on Twitter (COT) and implementing this discussion-based activity on a topic relating to American politics during one class session.

Sweet-Cushman found, through her social media-driven research, that students were competent at finding varied sources of information on the topic given to them, and they drifted away from their biases and allowed the discussion to change based on information shared by their classmates. This is consistent with Chris Bail's findings about the behavior of moderates, and in troll-free spaces, on online platforms (Bail 2021). According to Sweet-Cushman, Twitter also engaged students that normally did not participate in class and influenced all students to continue their online conversations once the activity had ended. The author also found that those who previously utilized social media to learn about new subjects, or to read the news, were more likely to feel confident in their ability to identify reliable information following the activity and felt encouraged to continue getting information from online sources. Ultimately, this research yielded results that support the assertion that social media can be an effective tool for educating students on civic and political processes, news, and debates and that social media can engage students who are otherwise unlikely to participate actively in class discussions.

While digital media can be an effective way for students and educators to learn more about politics and civic life, it can also be used for students to participate actively in these debates in long or short form essays, as detailed in Christopher N. Lawrence and Michelle L. Dion's article, "Blogging in the Political Science Classroom" (Lawrence and Dion 2010). Lawrence and Dion explain that blogs, while useful for providing opinion pieces and essays for students to read and learn from, can also be used by students to engage in political conversation while improving their competency in areas such as critical reading and thinking, research, political awareness, essay writing, and reflection.

Lawrence and Dion provide educators with knowledge and advice about how to implement blogging activities into their civically engaged classrooms. The authors assert that instructors must pay careful attention to the curriculum and the value that blogging can bring to the required lessons. They should be implemented intentionally, and the educator should know prior to assigning the blog posts if they will replace other writing activities and how much each student will be asked to contribute to their blog. The authors specifically provide examples of response blogging, in which students react to and discuss current events, and experiential blogging where students write about their lived civic experiences. In an age when bloggers are an important part of the media landscape, students gain professional, academic, and civic skills through blogging about civic life.

Conversation and active participation in civic life is a valuable outcome of social and digital media usage in the classroom. However, it is also vital for students to learn how to engage in this discourse in a way that values empathy and healthy communication over winning and undermining the views of others. Leslie Caughell addresses this topic in the article, "Teaching Students to Hear the Other Side: Using Web Design and Election Events to Build Empathy in the Political Science Classroom" (Caughell 2018). This research was conducted as part of a class titled, "Political Behavior in the American Electorate" and used web design and election events to encourage the cultivation of empathy within the classroom. Students were randomly assigned a 2016 Republican presidential candidate and tasked with creating a campaign website using knowledge they had gained about political motivations and behaviors and were then asked to write a paper about their decision-making process. 
As a result of this project and through pre- and post- project surveys, Caughell found that students were able to find information on their assigned candidate, policy positions, and backgrounds. Overall, students believed that they learned about their candidate throughout the course of the project, they held more favorable opinions about their candidate than they did when the project began, and they felt that they had gained valuable skills that would be professionally marketable. The use of technology and random candidate assignments encouraged students to step out of their preconceived notions about candidates and their political affiliations to understand what their true positions are and how they hope to effect change, thus creating more empathy for opposing viewpoints.

\section{Facilitating civil discourse in a pluralistic society}

For people to govern themselves, they need information and the ability to convey that information to others. They need an opportunity to share their challenges and suffering in ways that demonstrate the public, versus private, nature of many widespread social problems. Ideally, citizens can work to solve social problems and build social capital together, seeing each other as people with common experiences, interests, and needs (Sunstein 2018). For these reasons, social media is useful in a democracy. Unfortunately, the decision of social media companies to provide hyper-personalized experiences, and to use algorithms that reward Internet trolls and extremists with extra exposure, while limiting people's exposure to moderate views and to materials and arguments they would not have chosen in advance, undercuts the democratizing potential of social media (Bail 2021, Sunstein 2018). Such algorithms limit encounters with alternative perspectives and lead users to view each other as strangers, foreigners, or even enemies, which increases the likelihood of fragmentation, polarization, and extremism (Sunstein 2018). In addition, to make productive use of information, citizens must be able to distinguish between truth and falsehood - and to recognize when democratic processes are being manipulated. While disagreement about the truth is expected, when people knowingly spread lies it limits citizens' ability to discern the truth and establish a factual basis for policy discussions, debates, and deliberations (Sunstein 2018).

Some would point to social media as ground zero in the rise of civic discord and vitriol in our political discourse. The use (and abuse) of social media platforms like Twitter have contributed to divisions in the body politic, but to be effective, civic educators must meet students where they are; this includes using the communication tools they use. In the previously referenced, "Social Media Learning as a Pedagogical Tool: Twitter and Engagement in Civic Dialogue and Public Policy," Jennie Sweet-Cushman cites the coincident rise in social media use with an increase in disengagement among college students as a motivating factor in her exploration of possibilities for incorporating Twitter into students' Personal Learning Environment (PLE). A PLE consists of the tools, communities, services, and learning platforms used by individual learners to direct their own learning and pursue educational goals (SweetCushman 2019).

Sweet-Cushman explores whether Twitter has the potential to equip students with media literacy skills. Does such pedagogy have the potential to engage students less amenable to traditional classroom delivery? Can students be trained to employ new skills in their everyday interactions with others? Sweet-Cushman's research highlights students' awareness that social 
media platforms are "frequently a bad source of information," but that students for whom Twitter was part of their "natural environment" were capable and motivated to navigate the platform to become better informed about current political issues (Sweet-Cushman 2019, 769).

Digital media platforms can serve as a conduit to meaningful political engagement, and despite the tendency to reinforce tribal divisions, they can also be used to bridge ideological divides. As discussed above, Leslie Caughell (2018) found that requiring students to develop a web site for political candidates who may represent positions contrary to the students' personal positions led to increased empathy for the candidates and increased respect for differing views. Empathy is a critical skill to cultivate to improve discourse across political divides and to pursue policies that benefit those who need them most as well as policies for the collective good. Projects like Caughell's demonstrate the democratic potential of technology and also the importance of cross-disciplinary approaches to civic engagement and public policy-making. To be successful in deliberating, developing a message, and sharing that message, one must develop skills typically associated with communication and public relations more than political science, though working within the political system to shape public policy certainly requires knowledge and skills learned in the political science classroom.

Effective communication across ideological, socio-political boundaries are crucial elements in promoting pluralism and some articles took this issue head-on by using debates as classroom tools. In "Debating the Issues and Finding a Middle Ground," Sara Rinfret uses debate panels to deal with controversial subjects (Rinfret 2012). The panels provide active/experiential learning to help students become informed participants of US policymaking. The issues debated can include a wide spectrum of topics, allowing instructors to adapt and apply this model in crossdisciplinary and interdisciplinary ways, as campuses and departments integrate civic engagement principles into a broader range of subjects across the curriculum.

Rinfret responds to the tendency to deal with controversial issues in our public discourse in a bi-modal manner - taking stands on complex topics in a simple binary way, either for or against. She counters the critique that debates can contribute to such polarity (Trumpoksy 2004) by arguing for the active learning advantages they offer and the pedagogical benefits of students engaging in "deciphering political and scientific facts" (Rinfret 2012, 527). Rinfret counters Trumpoksy's view that "debate within the classroom only engenders additional dualism,"(Trumpoksy 2004) by arguing that the process of preparing for a debate panel compels students to develop more complex understanding of substantive policy issues, leading to a greater likelihood that they'll develop the tools required to engage in nuanced policy development.

Any methods that enhance discourse and civic dialogue are at a premium, and Rinfret's article is presented in sufficient detail so that these debate panels can be replicated to serve as active or experiential learning exercises in a wide array of educational settings. Rinfret shares the debate panel rubric she uses to evaluate student performance as well as the student feedback instruments she uses to assess increases in civic knowledge and other civic learning outcomes. Assessment mechanisms also included an open-ended question about student's ability "to consider a middle ground when examining public policy issues more broadly." Results indicate that students' civic knowledge was enhanced. In addition to fostering more openness in considering perspectives different from their own, many students came to recognize the 
limitations of the bi-modal lens through which many public policy debates are considered in our civic discourse. This insight is useful as we wrestle with how to bring civility and reason to our public discourse.

Helping students recognize the complexity inherent in discussions of public policy is critical in improving our civic discourse. Rinfret offers a detailed template for a course designed to help students recognize and dialogue around subtlety and nuance in issues of public policy. This template is actionable and broadly relevant across a range of disciplines relating to public policy and would be easily implementable given the details offered in Rinfret's article.

\section{Other Actionable, Practical, and Broadly Relevant Articles}

Notwithstanding the themes of APSA's 2021 conference, the paramount concern of this literature review is to distill findings from recent scholarship on civic engagement in ways that will be actionable and useful to political scientists and educators across disciplines and at different educational levels. This goal is a response to the urgency of our current national and international political context. To encourage further practice and research, the following articles offer useful lessons and best practices that facilitate replication and utilization in other contexts.

As noted in the preceding paragraphs, Risley, Mitchell and Coll all describe courses that integrate community engagement and in-class learning. While much of the work published on teaching civic engagement focuses on experiential learning outside of the classroom context, arguing that such experience leads to knowledge and skills as well as political engagement, is it possible that such attributes can be cultivated entirely within a classroom context? Does engagement have to be lengthy or sustained over time to boost students' civic and political engagement, or can political engagement be cultivated by brief classroom-based interventions? Promoting pluralism in methods demands that we consider the full range of interventions bolstering civic engagement. In "I will Register and Vote, If You Teach Me How: A Field Experiment Testing Voter Registration in College Classrooms," Bennion and Nickerson present rigorous research done on a large scale (including 25,256 students enrolled in 1,026 classrooms at 16 different campuses) to assess whether a relatively simple intervention could impact students' voter registration and voting rates (Bennion and Nickerson 2016). This study measured the impact of in-class presentations encouraging students to register to vote. The multiplicity of reasons that students have lower registration and voting rates presents a rich opportunity to bolster civic engagement through voter registration drives and substantial resources are invested each election cycle to do this. This study invested considerable effort in producing solid, measurable results of an intervention that required a brief classroom presentation encouraging students to register and providing registration forms in the class. The results show a positive impact on both registration and turnout. Unlike much research in civic engagement, this study involved verified behavioral data (I.e., official voter files) and random assignment (into a professor, peer, or control group) that allowed the authors to isolate and measure the specific effect of the classroom presentations. With such a simple intervention having such a significant impact, a compelling case can be made that implementing such tactics should be explored by all institutions of higher learning. Interestingly, little difference was found in the results between a professor making the pitch and a fellow student making the pitch, which seems to indicate that the operative factor in engaging students was that they were a captive audience forced to briefly focus on the issue of voter registration. This article also underscores 
the value of intercampus collaboration and rigorous quantitative research carried out on a broad scale. This study indicates that aggressively working within the closed context of the classroom can have a direct effect on students' electoral engagement providing an excellent return on investment.

One imperative behind promoting plurality is to expand the audience we are engaging for civic education beyond self-selected university students studying political science. In Wayne Journell's article, "We Still Need You! An Update on the Status of K-12 Civics Education in the United States," (Journell 2015) he revisits a topic addressed in a 2001 PS: Political Science and Politics article by Richard Niemi and Julia Smith on high school civics and government course enrollments which argued that political scientists are neglecting this important area of American civic life (Niemi and Smith 2001). Journell updates research from the previous study that examines data on enrollment in civic and social studies courses and attributed some increases in these areas to governmental mandates accompanying "No Child Left Behind" and other state K-12 educational requirements. He also cites new data on the impact of servicelearning programs as predictors of civic engagement in adulthood. While enrollment data may show improvements, questions still remain about the quality of that education. Moreover, Journell shows that concerns remain over the efficacy of civic education K-12 and its correlation to race and socio-economic status. Journell also posits that most states lack the kind of disciplinary knowledge laid out by APSA's committee on pre-collegiate education as standards for K-12 civics teachers. In short, while enrollment data remains healthy, it is the quality of civic education that is lacking, but there has been little involvement of political scientists in this issue. Journell supports his case by citing the lack of research on K-12 civics in research journals and recommends that political scientists need to publish in social study journals and present research at national educational conferences.

While Journell's overall point remains important and valid today, as close readers of the civic engagement literature, we would point out the valuable work of Shawn Healy (2017) regarding the type of social supports schools need to provide high quality civic education and the impressive body of research conducted by Diana Owen and colleagues regarding the quality, quantity, and type of civic education in junior high and high school affects students' long-term civic knowledge and engagement (see, for example, Owen 2013, 2017). We would also point to the new (2021) Roadmap for $21^{\text {st }}$ Century History and Civic Education funded by the National endowment for the Humanities and the U.S. Department of Education. The Roadmap, entitled Educating for American Democracy, was developed in consultation with with hundreds of experts in civics, U.S. history, political science and education with the goal of supporting the development of all students into prepared, informed and engaged citizens (Roadmap 2021).

There was also a single essay in "The Profession" section of PS by Elizabeth C. Matto and Timothy Vercellotti's entitled, "Methodological Lessons Learned from Conducting Civic Education Research in High Schools." This piece provides a helpful tool for those seeking to implement Journell's call for greater engagement with High School students (Matto and Vercellotti 2012). The essay was drawn from an earlier essay published elsewhere, about an experience they had conducting an experiment measuring generational differences in how civic attitudes are cultivated during high school (Vercellotti and Matto 2010). 
Particularly germane to this discussion is how Matto and Vercellotti use their experience in conducting this study to summarize some of their challenges in methodological issues that should be useful for anyone designing studies working with these populations of students. Recognizing the need for a how-to guide for conducting political science research in high schools, they enumerated some of the challenges that others might be prepared for who engage in this task. Notwithstanding decades of studies on the political formations of adolescents, there has been a dearth in reporting on the unique challenges entailed in winning the cooperation of school administrator and teachers, gaining consent from parents and collecting data from teens about political attitudes. The authors seek to remedy this deficit.

Among the wealth of lessons learned through the Matto and Vercelotti study is that researchers working in a high school should be cognizant of the schedule and environment in which they are gathering data. Other lessons offered include the need for researchers to have intermediary advocates to communicate the benefits of their study to administrators and faculty as well as incentives for participating, such as gift cards to increase buy-in among students and teachers. Research involving the educational environment can be unpredictable, and the lessons shared in this article will go a long way in helping researchers who hope the study civic engagement among high school students.

Ideas on better reaching high school students by focusing on teaching high school teachers is also presented in Smith and Graham's article, Teaching Active Citzenship, cited earlier, in which they emphasize their curriculum on Teaching Active Citzenship should be given priority in teachers' colleges and curricula utilized in training educators (Smith and Graham 2014).

The need for institutional support to support civic engagement pedagogies is a recurrent theme in many of these articles and Karen Kedrowski and Kararine Moyon show how South Carolina's Winthrop University took advantage of the state's early presidential primary to encourage civic engagement in "Becoming a Stop on the Road to the White House: Using a University Protocol to Govern Candidate Visits" (Kedrowski and Moyon 2016). The high profile of presidential elections presents opportunities to reach students outside the political science orbit and advice for how to take advantage of these opportunities given the imperative for colleges and universities to heighten civic engagement.

Citing the plethora of indicators on declining civic engagement, including the lowest turnout in history for 18-24-year-olds in the 2014 midterm election, the authors cited multiple efforts to increase access to information - especially for first-time voters - as a significant endeavor to ameliorate the problem. More information and direct exposure to the election process is cited as one of the highest leverage activities to engage young and first-time voters. Accordingly, Winthrop University embarked on a two-year planning process to host a series of presidential candidate visits in advance of the 2016 Presidential primary season. Their article provides a template that can be emulated by institutions across the country. They provided historical background on Winthrop's role in similar candidate events from previous elections cycles. Acknowledging their advantages as an early primary state, they suggest that institutions could build their capacity by first focusing on legislative elections with stronger local ties. 
The authors share the University's "Candidate Visit Protocol" and provide a template that could be used by any university seeking to take advantage of high-profile campaigns to encourage university-wide civic engagement. Kedrowski and Moyon also share some of the lessons they learned from the process to benefit those who might wish to replicate these kind of civic engagement activities. In short, this basic how-to guide can be useful for any institution which seeks to improve its civic engagement culture and voter turnout, which is something that virtually all institutions of higher learning are being called upon to do.

\section{Important Directions for Future Research}

The articles represented in this review cover a wide range of topics, research questions, and methods related to civic engagement and education. However, the field is still lacking evidence and research in several areas. There is a need for more assessments completed over a greater length of time. While a wealth of assessment tools and methods are offered, many of these occur over the course of a single semester or after one project, and the long-term benefits or consequences are not assessed outside of the time in which the class is offered. This raises questions about the long-term efficacy of these teaching methods. It would be useful, for example, to follow up with students who participated in these research projects after a year or more to assess how the method impacted their level of political and community engagement.

Many authors suggest that a more long-term approach to experiential learning allows students to become intimately aware and involved in community issues and political processes. While a one day or week experiential learning exercise may surprise students and teach them something about a community or group, it is unclear if this directly translates to sustained action and awareness. A short-term project can be useful for educators that are beholden to strict curriculum or time constraints, but more research is needed to determine the true utility of these projects, and their more lengthy, time-intensive counterparts.

Civic and political engagement through social and digital media is a new and exciting platform for educators and students to discuss and use as a vehicle for participating in political initiatives. The articles referenced here show that social media can, in fact, complement classroom learning by allowing students to apply their knowledge in debates, persuasive messaging, and informative writing, while aiding in increasing informational literacy. Further research is essential to understanding how the impact of digital civic engagement translates into the real world. Educators and researchers should concern themselves with determining the effect of digital engagement on voter turnout, volunteering, community organization participation, political efficacy, and community improvement and change. Moreover, since much of the discord in contemporary political dialogue is manifested in divisiveness on social media platforms, efforts that explore utilization of such platforms to improve civic discourse should be energetically explored. There is a clear benefit and need for activism and engagement in the digital realm, but we should ensure that this does not overshadow the need for direct participation in community processes and initiatives.

Finally, there is a clear and present need for more civic engagement and political education in political science and in other disciplines. APSA president-elect John Ishiyama is expected to announce a major initiative to rethink the political science major. A taskforce working with 
Ishiyama on this task over the past several years has proposed that civic engagement should be a central part of the undergraduate curriculum. We agree that educating citizens for democracy should be a central goal of the major, but also agree with authors of The Crucible Moment (2012) and Educating Citizens for Democracy (Colby et al. 2003) that such education should not be confined to political science courses. Additional research is needed regarding the implementation of civic education and engagement initiatives across disciplines and academic institutions. Because of the siloing that is present in many of these institutions, it is vital to our civic wellbeing to ensure that civic engagement is being taught in a way that is relevant and applicable to all students, regardless of their major. This may present a challenge for institutions and disciplines that already struggle with sustaining collaborative efforts or implementing new initiatives. Regardless, if the institution values civic engagement and knowledge, it should prioritize a comprehensive curriculum addressing these topics for all students, not just those in the social and political sciences.

\section{Conclusion}

One of the challenges of implementing robust civic engagement curricula is the amount of effort required to implement the multifarious elements required when using methods like servicelearning, simulations, and various other forms of community engagement, including communitybased research. These challenges may limit a particular instructor's capacity to implement comprehensive evaluations while managing the course and grading students. A good many of these articles lay out details for formulating a particular class or best-practices for a specific line of research. By sharing these with the broader academic community, these writers invite others to contribute to the dialogue and expand opportunities to teach and to learn. By sharing their experiences, they invite further reflection and feedback, while offering critical information to future instructors who can use backward design to start with learning objectives and build assessment into the original course, program, or curriculum design. Our goal is to amplify this invitation.

The time is right to answer this call and to support teacher-scholars who take the next step. The newly formed Civic Engagement Section of the American Political Science Association (https://bit.ly/apsacivic) is poised to provide year-round professional development programming, mentoring, and collaborative publishing opportunities, as well as annual awards for innovative junior scholars, senior scholars, papers, and projects in the civic space. The section, which has already launched a Spotlight series in PS: Political Science and Politics and a special issue of the e-Journal of Public Affairs, is building on the work of the Political Science Education Section, including the launch and success of the Journal of Political Science Education and the APSA Teaching and Learning Conference, both of which have significant content in the area of teaching civic engagement. Meanwhile, the APSA just published the third book in its Teaching Civic Engagement series entitled Teaching Civic Engagement Globally (Matto et al. 2021). The APSA now provides several online resources for civic educators including the APSA Educate website, APSA's Raise the Vote campaign, resources for public engagement, and sponsorship of the Alma Ostrom and Leah Hopkins Awan Civic Education Fund of the APSA Centennial Center and the establishment of the APSA Distinguished Award for Community and Civic Engagement, and the creation of the APSA Institute for Civically Engaged Research (ICER).

Given the challenges inherent in designing civic engagement pedagogies, institutional support from instructor's home institutions is also crucial and often lacking. Collaborations with 
community groups can be complex and require participation from multiple constituencies - often bringing differing agendas to the endeavor. Universities that provide incentives for civicengagement and that support well-run community engagement programs, may offer resources, including paid professional development opportunities to instructors aspiring to incorporate community engagement into their pedagogies. For example, by facilitating campaign events on campus, Winthrop University created civic learning opportunities for instructors to utilize and Rhodes College's strong community engagement orientation facilitated course designs reliant on an element of service-learning. These examples fit well within a larger national movement marked by the growth of the Carnegie Engaged Campus designation program, the explosion of non-partisan civic groups partnering with campuses to engagement college students in the political process, and the increased recognition of professional associations (e.g. AASCU, AAC\&U, APSA) that educating democracy is at the core of the mission of higher education in the United States.

We hope future researchers will pay special attention to assessing civic learning outcomes. The need to use various assessment methods for this growing field makes the task more complicated than simply teaching a course. Deploying rigorous assessment tools may, at times, seem burdensome, but the lessons they illuminate may help simplify the task over time. For example, the findings shared in the Bennion/Nickerson article give strong evidence for the efficacy of a relatively simple intervention to increase student voter registration and turnout, showing how an up-front investment in robust assessment tools may simplify civic engagement work going forward.

Many of the articles reviewed here are generous in sharing tools, templates and valuable lessons derived from first-hand experience. Our hope is that reviewing this small sample of the literature on civic engagement will help others to jump start their own research program and innovative new teaching practices as we continue to build our knowledge of how to best educate citizens for democracy. The civic mission of higher education is not limited to those with a particular legal status or from a particular state or nation. At a time of distrust and polarization, when support for democracy is waning and democratic institutions are under attack, it is critical that the next generation receive the education they need to rebirth our democracy. This moment demands an all-hands-on-deck approach, and our hope is that this paper will be useful in pointing practitioners to the hard work that has already been accomplished by our colleagues and in inspiring innovative and effective new approaches to promoting civic learning and democratic engagement. 


\section{References}

Anderson, Brian. "High-Impact Political Science Internships in a "Low-Density Opportunity" Environment." PS: Political Science \& Politics 47, no. 4 (2014): 862-866.

Bail, Chris. Breaking the Social Media Prism: How to Make Our Platforms Less Polarizing. Princeton, NJ, Princeton University Press, 2021.

Bennion, Elizabeth A. "Experiential Education in Political Science and International Relations." In Handbook on Teaching and Learning in Political Science and International Relations, eds. John Ishiyama, William J. Miller, and Eszter Simon. Northampton, MA: Edward Elgar Publishing, 2015.

Bennion, Elizabeth A., and David W. Nickerson. "I Will Register and Vote, If You Teach Me How: A Field Experiment Testing Voter Registration in College Classrooms." PS: Political Science \& Politics 49, no. 4 (2016): 867-871.

Berry, Michael J., and Tony Robinson. "An Entrance to Exit Polling: Strategies for Using Exit Polls as Experiential Learning Projects." PS: Political Science \& Politics 45, no. 3 (2012): 501505 .

Borowiak, Craig, Vicky Funari, Jesikah Maria Ross, and Helen K. White. "Troubled Waters: Tracing Globalization and Waste in the Delaware River." PS: Political Science \& Politics 50, no. 1 (2017): 193-198.

Cabrera, Luis, and Jeffrey Anastasi. "Transborder Service Learning: New Fronteras in Civic Engagement." PS: Political Science \& Politics 41, no. 2 (2008): 393-399.

Catlett, Rob. "Blending Elements of Economics and Political Science: Intergenerational Dialogue, Civic Engagement, and Related Student Scholarly Activity." PS: Political Science \& Politics 43, no. 2 (2010): 337-342.

Caughell, Leslie. "Teaching Students to Hear the Other Side: Using Web Design and Election Events to Build Empathy in the Political Science Classroom." PS: Political Science \& Politics 51, no. 3 (2018): 659-663.

Caulfield, Mike. "Check Please! Starter Course.” Published August 13, 2019. https://www.notion.so/checkpleasecc/Check-Please-Starter-Courseae34d043575e42828dc2964437ea4eed.

Caulfield, Mike. Web Literacy for Student Fact-Checkers. Vancouver, Washington State University: Mike Caulfield, 2017.

Colby, Anne., Tom Ehrlich, Elizabeth Beaumont, and Jason Stephens. Educating Citizens: Preparing America's Undergraduates for Lives of Moral and Civic Responsibility. San Francisco: Jossey-Bass, 2013.

Croco, Sarah E., Elizabeth Suhay, Rachel Blum, Lilliana Mason, Hans Noel, Jonathan Ladd, and Michael A. Bailey. "Student-Run Exit Polls 101." PS: Political Science \& Politics 52, no. 2 (2019): 361-366. 
Deitz, Janna L., and Keith Boeckelman. "Simulating 2008: A Mock Presidential Election's Impact on Civic Engagement." PS: Political Science \& Politics 45, no. 4 (2012): 743-747.

Dewey, John. The School and Society. Chicago, IL: University of Chicago Press, 1915.

Healy, Shawn P. Essential Supports for Civic Learning. In Teaching Civic Engagement across the Disciplines, eds. Elizabeth Matto, Alison Rios Millett McCartney, Elizabeth A. Bennion, and Dick Simpson. Washington, DC: American Political Science Association, 2017.

Jenkins, Shannon. "Service Learning and Simulations." PS: Political Science \& Politics 43, no. 3 (2010): 541-545.

Journell, Wayne. "We Still Need You! An Update on the Status of K-12 Civics Education in the United States." PS: Political Science \& Politics 48, no. 4 (2015): 630-634.

Kedrowski, Karen M., and Katarina Duich Moyon. "Becoming a Stop on the Road to the White House: Using a University Protocol to Govern Candidate Visits." PS: Political Science \& Politics 49, no. 4 (2016): 876-879.

Knecht, Thomas, and Lisa M. Martinez. "Engaging the Reluctant? Service Learning, Interpersonal Contact, and Attitudes Toward Homeless Individuals." PS: Political Science \& Politics 45, no. 1 (2012): 106-111.

Kwak, Joonghyun, Irina Tomescu-Dubrow, Kazimierz M. Slomczynski, and Joshua K. Dubrow. "Youth, Institutional Distrust, and Democratic Backsliding." The Behavioral Scientist 64, no. 9 (2020): 1266-1390.

Lawrence, Christopher N., and Michelle L. Dion. "Blogging in the Political Science Classroom." PS: Political Science \& Politics 43, no. 1 (2010): 151-156.

Mann, Christopher B., Gayle A. Alberda, Nathaniel A. Birkhead, Yu Ouyang, Chloe Singer, Charles Stewart, Michael C. Herron et al. "Pedagogical Value of Polling-place Observation by Students." PS: Political Science \& Politics 51, no. 4 (2018): 831-837.

Matto, Elizabeth C., Alison Rios Millett McCartney, Elizabeth A. Bennion, and Dick W. Simpson, eds. Teaching Civic Engagement Across the Disciplines. Washington, DC: American Political Science Association, 2017.

Matto, Elizabeth C., Alison Rios Millett McCartney, Elizabeth A. Bennion, Alasdair Blair,Taiyi Sun and Dawn Michele Whitehead, eds. Teaching Civic Engagement Globally. Washington, DC: American Political Science Association, 2021.

Matto, Elizabeth C., and Timothy Vercellotti. "Methodological Lessons Learned from Conducting Civic Education Research in High Schools." PS: Political Science \& Politics 45, no. 4 (2012): 728-735.

McDonald, Michael K. "Civic Engagement with an International Focus: The Western Carolina Microfinance Project." PS: Political Science \& Politics 46, no. 4 (2013): 797-801. 
McInerney, Chris, and Maura Adshead. "Problem-Based Learning and Civic EngagementShifting the Focus of Learning in Public Policy Education.” PS: Political Science \& Politics 46, no. 3 (2013): 630-636.

Mitchell, Tania D., and Kathleen M. Coll. "Ethnic Studies as a Site for Political Education: Critical Service Learning and the California Domestic Worker Bill of Rights." PS: Political Science \& Politics 50, no. 1 (2017): 187-192.

National Task Force on Civic Learning and Democratic Engagement. "A Crucible Moment: College Learning \& Democracy's Future.” Washington DC: Association of American Colleges and Universities, 2012. Niemi, Richard G., and Julia Smith. "Enrollments in High School Government Classes: Are We Short-changing Both Citizenship and Political Science Training?." PS: Political Science \& Politics 34, no. 2 (2001): 281-287.

Owen, Diana. "The Influence of Civic Education on Electoral Engagement and Voting." In Teaching Civic Engagement: From Student to Active Citizen, eds. Alison Rios Millett McCartney, Elizabeth A. Bennion, and Dick Simpson. Washington, D.C.: American Political Science Association, 2013.

Owen, Diana and G. Isacc W. Riddle. "Active Learning and the Acquisition of Political Knowledge in High School. In Teaching Civic Engagement across the Disciplines, eds. Elizabeth Matto, Alison Rios Millett McCartney, Elizabeth A. Bennion, and Dick Simpson. Washington, DC: American Political Science Association, 2017.

Rittel, Horst W. J., and Melvin M. Webber. (1973). "Dilemmas in a General Theory of Planning." Policy Sciences 4, no. 2 (1973): 155-169.

Rinfret, Sara R. "Simulating City Councils: Increasing Student Awareness and Involvement." PS: Political Science \& Politics 45, no. 3 (2012): 513-515.

Rinfret, Sara R., Justin Angle, Samuel Scott, Daisy Ward, Kaixuan Yang, Emily Copeland, Rebecca Power, Thomas Ray, and Thomas Hiett. "Experiential Learning Revisited: Lessons from a Student-Led Public Opinion Polling Class." PS: Political Science \& Politics 53, no. 3 (2020): 542-546.

Risley, Amy. "Think Globally, Act Locally: Community-Engaged Comparative Politics." PS: Political Science \& Politics 52, no. 4 (2019): 733-736.

Simeone, James, James Sikora, and Deborah Halperin. "Unscripted Learning: Cultivating Engaged Catalysts." In Teaching Civic Engagement Across the Disciplines, edited by Elizabeth

Sunstein, Cass R. "Is social media good or bad for democracy." Sur - International Journal on Human Rights 27 (2018): 83.

C. Matto, Alison Rios Millett McCartney, Elizabeth A. Bennion, and Dick W. Simpson, 273. Washington, DC: American Political Science Association, 2017.

Smith, Michael, and Bob Graham. "Teaching Active Citizenship: A Companion to the Traditional Political Science Curriculum." PS: Political Science \& Politics 47, no. 3 (2014): 703 710 . 
Sunstein, Cass R. "Is social media good or bad for democracy." SUR-International Journal on Human Rights. 27 (2018): 83.

Sweet-Cushman, Jennie. "Social Media Learning as a Pedagogical Tool: Twitter and Engagement in Civic Dialogue and Public Policy." PS: Political Science \& Politics 52, no. 4 (2019): 763-770.

Theis, John J. "Political Science, Civic Engagement, and the Wicked Problems of Democracy." New Directions for Community Colleges 2016, no. 173 (2016): 41-49.

Tumposky, Nancy Rennau. "The Debate Debate." The Clearing House: A Journal of Educational Strategies, Issues and Ideas 78, no. 2 (2004): 52-56.

Turner, Charles C. "Civic Engagement in the Capstone: The "State of the Community" Event." PS: Political Science \& Politics 47, no. 2 (2014): 497-501.

Vercellotti, Timothy, and Elizabeth C. Matto. "The Role of Media Use in the Classroom and at Home in Improving News Consumption and Political Knowledge." Journal of Political Science Education 12, no. 2 (2016): 151-168.

Westheimer, Joel, and Joseph Kahne. "Educating the "Good" Citizen: Political Choices and Pedagogical Goals." PS: Political Science \& Politics 37, no. 2 (2004): 241-247. 